\title{
La construcción del Ethos en informes de laboratorio producidos por estudiantes universitarios: contrastes en el discurso académico en español
}

\author{
A construção do ethos nos informes de laboratorio produzidos pelos estudantes universitarios: \\ contrastes no discurso acadêmico em espanhol
}

\section{Construction of ethos in laboratory reports of university students: contrasts in academic discourse in Spanish}

Enrique Sologuren Insua $\oplus^{1}$

María Natalia Castillo Fadic ${ }^{2}$

1 Pontificia Universidad Católica de Valparaíso (PUCV), Valparaíso, Chile 2 Pontificia Universidad Católica de Chile (UC), Santiago, Región Metropolitana, Chile

Em memória do Dr. Lésmer Montecino

$\diamond$

\begin{abstract}
RESUMEN
En este artículo se analiza la constitución del ethos académico en un corpus de informes de laboratorio producidos por estudiantes universitarios de tercer año. El objetivo de esta investigación es doble: a) analizar mediante una aproximación cualitativa enmarcada en el análisis del discurso las estrategias discursivas y los recursos lingüísticos empleados por los estudiantes en la construcción de un ethos académico; b) relacionar esta construcción identitaria con dos tipos de informes según la evaluación realizada por el docente que demanda la producción de este género: aceptables y deficientes. Esta caracterización permitirá comprender la forma en que el estudiante construye una voz y una imagen académica en un género discursivo particular, en un determinado estadio de formación. Para abordar el objeto de estudio, se recurre a plataformas teóricas metodológicas diversas, pero convergentes en variados lineamientos: el Análisis del Discurso semiodiscursivo (CHARAUDEAU, 2004), los estudios de literacidad crítica (IVANIC, 1998, 2005) y los estudios sobre el Discurso Académico y los géneros académicos (HYLAND, 2002, 2005; SWALES, 2004). El corpus sobre el que operamos está conformado por 9 informes de laboratorio del área de la ingeniería eléctrica. La propuesta investigativa es de carácter descriptivo y eminentemente cualitativa. Los procedimientos metodológicos buscan vincular el uso de ciertas estructuras lingüísticas preferidas en los textos con los diferentes elementos de la situación de enunciación. Los resultados muestran la forma en que se actualizan diferentes estrategias discursivas y recursos lingüísticos, así como su funcionamiento prosódico en el entramado discursivo. Se concluye la relevancia de las estrategias discursivas empleadas en los procesos de formulación y reformulación discursiva, al permitir el surgimiento de zonas sensibles para la emergencia del sujeto y su posicionamiento en la disciplina del saber concernida.
\end{abstract}

Palabras clave: Ethos discursivo. Discurso académico. Identidad. Textos producidos por estudiantes universitarios. Contrato de comunicación. Estrategia de discurso.

\section{RESUMO}

Neste artigo se analisa a constituição do ethos acadêmico em um corpus de informes de laboratório produzidos pelos estudantes universitários de terceiro ano. O objetivo desta investigação é duplo: a) analisar mediante uma aproximação qualitativa emarcada na análise do discurso as estrategias discursivas e os recursos linguísticos empregados pelos estudantes na construção de um ethos acadêmico; b) relacionar esta construção identitária com dois tipos de informes segundo a avaliação realizada pelo docente que demanda a produção deste gênero: aceitáveis e deficientes. Esta caracterização permitirá compreender a forma em que o estudante constrói uma voz e uma imagem acadêmica em um gênero discursivo particular, em um determinado estadio de formação. Para abordar o objeto de estudo, se recorre a plataformas teóricas metodológicas diversas, mas convergentes em variados lineamentos: a Análise do Discurso semio-discursiva 
(CHARAUDEAU, 2003), os estudos do letramento crítico (IVANIC, 1998, 2005) e os estudos sobre o Discurso Acadêmico e os gêneros acadêmicos (HYLAND, 2002, 2005; SWALES, 2004). O corpus sobre o qual operamos está conformado por 9 informes de laboratorio da área da ingenharia elétrica. A proposta investigativa é de caráter descritivo e eminentemente qualitativa. Os procedimentos metodológicos procuram vincular o uso de certas estruturas linguísticas preferidas nos textos com os diferentes elementos da situação de enunciação. Os resultados mostram a forma em que se atualizam diferentes estrategias discursivas e recursos linguísticos, assim como seu funcionamento prosódico no entramado discursivo. Conclui-se a relevancia das estrategias discursivas empregadas nos processos de formulação e reformulação discursiva, ao permitir o surgimento de zonas sensíveis para a emergência do sujeito e seu posicionamento na disciplina do saber concernida.

Palavras chave: Ethos discursivo. Discurso acadêmico. Identidade. Textos produzidos por estudantes universitarios. Contrato de comunicação. Estrategia de discurso.

\begin{abstract}
The construction of academic ethos is analyzed in this article based on a corpus formed by laboratory reports written by third-year university students. It has two aims: a) to analyze discursive strategies and linguistic resources used by students in the construction of an academic ethos through a qualitative approach within the discourse analysis field; b) to stablish a link between the identity construction and two types of reports, the acceptable ones and the unsatisfactory ones, based on the evaluation made by the professor who requested the report. The characterization will help to understand how the student constructs an academic image in a determined discursive genre, in a specific stage of formation. In order to work the object of study, different theoretical and methodological platforms but that converge several lineaments are used, such as semiodiscoursive discourse analysis (CHARAUDEAU, 2003), critical literacy studies (IVANIC, 1998, 2005) and Academic discourse and academic genres (HYLAND, 2002, 2005; SWALES, 2004). The corpus is formed by 9 laboratory researches in the electrical engineering field. The research proposal is descriptive and predominantly qualitative. The methodological procedure seeks to link the use of certain preferred linguistic structures in texts and the different elements involved in the enunciation circumstance. The results show how different discursive strategies and linguistic resources are updated, as well as the prosodic performance in the discourse structure. Finally, the relevance of the discursive strategies used in the discursive formulation and reformulation processes is found as a conclusion, as it allows the emergence of the subject appearance and the positioning of it within the related knowledge discipline.
\end{abstract}

Keywords: Discursive ethos. Academic discourse. Identity. Texts written by university students. Communication contract. Discourse strategy.

\section{Introducción}

En las comunidades académicas, el discurso escrito tiene una fuerte presencia en la práctica académica (PARODI, 2008); se actualiza en una gran diversidad de géneros comunicativos a través de los cuales los integrantes de la comunidad de práctica universitaria transmiten, construyen y organizan el conocimiento disciplinar. Así, estudiantes, docentes e investigadores participan en diferentes actividades comunicativas de carácter oral y escrito, mediante las cuales deben manifestar una determinada competencia y actualizar diferentes estrategias lingüísticas, textuales y pragmáticas para cumplir con variados propósitos de orden disciplinar, retórico, social, afectivo e interaccional, ya que "Una disciplina es un espacio discursivo y retórico tanto como conceptual" (BOGEL; HORTSHOJ, 1984, p. 14).

En los últimos años, estudiosos de la comunicación académica provenientes de diferentes corrientes disciplinares, tales como la Lingüística Sistémica Funcional, la Sociolingüística y la Teoría de los Géneros, entre otras (SALAGER-MEYER, 2007; HYLAND, 2002; 2005; HUNSTON; THOMPSON, 2000), han demostrado que el discurso académico no se limita a la transmisión ordenada, clara y precisa de determinados contenidos, sino que posee una dimensión retórica e interpersonal fundamental para el éxito de la interacción con la audiencia.

Dentro de la variedad de recursos propios del discurso académico, se han investigado las variadas formas de atenuación o hedges (HYLAND, 2005) las referencias al autor (HYLAND, 2002; 2005), los comentarios de autor, las citas (SWALES, 2014), la evaluación (HUNSTON; THOMPSON, 2000; THOMPSON, 2009; MARTIN; WHITE, 2005) y las expresiones directivas (HYLAND, 2012). La reflexión sobre el sujeto enunciador y en especial sobre las manifestaciones de la subjetividad y de la evaluación en los textos académicos es otra área 
que presenta un desarrollo considerable (IVANIC, 1998; TANG, JOHN, 1999; BREIVEGA; DAHL; FLØTTUM, 2002) todas estas investigaciones han puesto de manifiesto que el locutor del discurso científico académico deja huellas de su presencia y no es ni monológico ni neutro (GARCÍA-NEGRONI, 2008) por lo que estos elementos deben ser considerados en el análisis de la producción discursiva.

No obstante, se requieren más investigaciones que indaguen en los textos producidos por los estudiantes universitarios en diferentes estadios de su trayecto formativo y en la construcción progresiva de su identidad como un factor determinante en la apropiación de los géneros propios de su comunidad, así como en la construcción de una voz académica propia y singular. El estudio que se informa intenta responder las siguientes preguntas: a) ¿Cómo se construye el ethos académico en los informes de laboratorio del área de Ingeniería Eléctrica? Siendo el informe de laboratorio un género de formación (SWALES, 2004) cuyo resultado final es evaluado por un profesor, b) ¿Qué relación existe entre la construcción de un determinado ethos discursivo y el éxito o fracaso estudiantil?

El objetivo de nuestro estudio es doble: a) por un lado, analizar las estrategias discursivas y los recursos lingüísticos que son empleados por los estudiantes en la construcción de un ethos académico y, b) por otro lado, relacionar esta construcción identitaria con informes considerados exitosos y con informes categorizados como deficientes por los profesores que demandan la producción de este género.

Este trabajo desarrolla primeramente algunos útiles conceptuales que permitan abordar la problemática de la construcción de la identidad en el discurso académico en formación; en segundo lugar, explicita los procedimientos metodológicos y contextualiza el corpus de estudio; posteriormente, presenta una descripción de los principales resultados y finalmente sintetiza los hallazgos más relevantes y discute las implicancias que una aproximación de este tipo posee para el estudio de las identidades, de las imágenes y de las voces en los textos de los aprendices en una comunidad disciplinar.

\section{Marco teórico}

\subsection{El informe de laboratorio como género académico}

La alfabetización académica como programa de investigación y de intervención (CARLINO, 2009; MARINKOVICH, 2014) ha puesto en evidencia la preocupación por el desarrollo de habilidades comunicativas en el ámbito de la Educación Superior. En efecto, analistas del discurso, especialistas en didáctica de las lenguas y estudiosos de los géneros del discurso han orientado sus esfuerzos a: a) detectar necesidades comunicativas (BAZERMAN, 1994), b) describir las características lingüísticas y discursivas de los textos que circulan en el ámbito académico (Especialmente la Escuela Lingüística de Valparaíso: PARODI, 2008; 2009: 2010 ; 2012) y c) proponer pasos que faciliten la inserción de los estudiantes en la cultura académica (CASSANY, 1995; MONTOLÍO, 2000; CARLINO, 2004; ARNOUX, 2009; MARINKOVICH, 2014) y el dominio de la escritura científica (SABAJ, 2012).

Estudios internacionales que se vienen desarrollando desde hace más de tres décadas en el ámbito angloparlante, francófono y, más recientemente en el ámbito hispánico, muestran la relevancia del desarrollo de competencias discursivas tanto para lograr establecer relaciones comunicativas eficaces al interior de las comunidades específicas como para facilitar los procesos de aprendizaje (ARNOUX; DI STEFANO; PEREIRA, 2002; BAZERMAN, 1988; BATHIA, 1993; CARLINO, 2005a; 2005b; TEBEROSKY, 2007).

La universidad como una comunidad de práctica particular requiere, para cumplir sus objetivos institucionales, resolver y satisfacer las necesidades comunicativas que manifiestan y evidencian los diferentes integrantes de la cultura académica. En este sentido, en la base de todas las investigaciones mencionadas emerge el diagnóstico sobre las carencias y debilidades en el ámbito de la competencia comunicativa necesaria para enfrentar con éxito las exigencias de la Academia $\mathrm{y}$, en consecuencia, se revela como pieza fundamental la necesidad de un proceso explícito y dirigido de alfabetización en las disciplinas universitarias. Esta necesidad se vuelve aún más fundamental si consideramos que la cultura académica es sumamente compleja y al interior de ella convergen diferentes prácticas discursivas, "distintas ideologías disciplinares, diferentes esquemas de pensamiento y variedades de lenguaje" (HARVEY, 2009, p. 628).

La universidad puede entenderse, en este sentido, como una comunidad discursiva o como una comunidad de práctica: a) en tanto comunidad discursiva es un "grupo sociorretórico en el cual los intercambios lingüísticos tienen fines funcionales, fundamentalmente los de mantener y extender el conocimiento del grupo, así como la de incorporar nuevos miembros" (SWALES, 1990, p. 25) -en este mismo ámbito, Lave y Wenger (1991) agregan una nueva noción que responde creemos de manera satisfactoria no sólo al contexto examinado por los autores, sino que también a la oralidad académica especializada-; b) en tanto comunidad de práctica refiere a aquellas relaciones de aprendizaje que se establecen no sólo entre un aprendiz y su maestro, sino que también 
involucran a otros, por ejemplo, a otros aprendices más avanzados, la actividad de aprender se concibe, entonces como un esfuerzo comunitario para la resolución de problemas o para la consecución de un fin práctico que considera la interacción grupal.

De lo anterior, podemos desprender que las comunidades de práctica se crean al interior de las instituciones educativas y se diferencian de la comunidad discursiva básicamente por ser grupos, inicialmente abiertos: "sin que necesariamente haya algún tipo de iniciación o incluso conciencia de pertenencia a una comunidad de este tipo" (HARVEY; MUÑOZ, 2006, p.98). Ambas nociones son especialmente útiles para comprender cómo al interior del entramado universitario coexisten, convergen y divergen diferentes culturas disciplinares que atraviesan la actividad discursiva de sus integrantes.

Aproximadamente desde la década de los años 80, diferentes disciplinas han abordado la historia y las funciones de los géneros disciplinarios (artículos de investigación, ponencias, conferencias, monografías, ensayos académicos, entre muchos otros). Bathia (1993), por ejemplo, ha concentrado su investigación en la comunicación legal, así como otros en la científica (HALLIDAY; HASSAN, 1989, HALLIDAY; MARTIN, 1993). Estudiosos de la retórica y de la comunicación han focalizado sus esfuerzos en el artículo experimental (BAZERMAN, 1988), la reseña de bibliografía en Ciencias Naturales (FREEDMANN, 1994) o los ensayos interpretativos (MILLER, 1984), entre otros. Así, los estudios sobre géneros han interesado no solo a lingüistas y analistas del discurso, sino que también a investigadores y docentes de diferentes disciplinas, que desean comprender mejor los tipos de textos que circulan en su comunidad de práctica.

En este contexto, siguiendo a Hyland (2011), entendemos el discurso académico como las diferentes formas de usar el lenguaje en el mundo de la academia. Como ya hemos planteado, este tipo de discurso es fundamental no solo para la transmisión y difusión del conocimiento, sino también para la incorporación de nuevos miembros, para acceder al conocimiento de una disciplina y para la co-construcción del conocimiento especializado. En este sentido, los textos producidos tanto por especialistas como por estudiantes que se encuentran en diferentes etapas de su trayectoria formativa requieren ser estudiados si entendemos que todos ellos, en tanto discursos, presentan usos contextualizados de acciones y representaciones sociales de las comunidades verbales "en función de sus necesidades, tendencias y objetivos" (LÓPEZ ALONSO, 2014, p. 16). Los discursos como práctica social, en ese sentido, no pueden ser disociados de las instituciones de las cuales emergen.
La escritura en el ámbito universitario, por tanto, cobra un papel fundamental en el medio académico, no solo por su participación crucial en el proceso de alfabetización académica o por su papel en el contexto global y en las industrias del conocimiento o en el desarrollo de una experticia interdisciplinaria (BATHIA, 2002), sino que también en la negociación de las identidades, en el posicionamiento en las disciplinas y en las relaciones de poder: "la escritura es una forma particularmente manifiesta de acción social para la negociación de identidades, porque un texto escrito es deliberado, potencialmente permanente y usado como declaración para muchos fines sociales (tal como la evaluación de logros académicos)" (IVANIC, 1998). Es así que en este marco nos interesa explorar la constitución de un ethos académico, la forma en que se construye la identidad en géneros académicos producidos por estudiantes, el grado de apego y obediencia a la comunidad de práctica que se manifiesta en determinadas elecciones y estrategias y su vínculo con el éxito o el fracaso estudiantil en la educación superior. Pero antes de abocarnos a ello necesitamos profundizar, desde el análisis del discurso, aquellas nociones claves que nos permitan enfrentar el estudio de la construcción identitaria: este es el objetivo fundamental del presente artículo.

El género informe académico ha sido definido como una interacción que cumple un propósito social particular dentro de las variadas prácticas discursivas utilizadas por los estudiantes en las carreras de pregrado y que permite estimar un nivel de desarrollo en un área disciplinar específica. En él participan un estudiante universitario como enunciador y un académico como destinatario, el que evalúa la aplicación de convenciones textuales-discursivas (HARVEY; MUÑOZ, 2006; NÚÑEZ et al., 2006).

Respecto de las características textuales y estructurales del informe académico en estudiantes de pregrado, Oyanedel (2005) ha expuesto la incidencia del componente descriptivo en la configuración de estos escritos. Asume en su análisis un punto de vista referido a las secuencias textuales y a la figura global del texto. Espejo (2006), por su parte, bajo un enfoque sociodiscursivo, se focaliza en la estructura del informe y diferencia una estrategia retórica o move (SWALES, 1990) que emplean estudiantes universitarios de tres áreas diferentes -Licenciatura en Letras, Psicología e Ingeniería Civil-al redactar la sección conclusión de los informes de investigación.

Otros estudios se han enmarcado en la construcción temática y la materialización discursiva en los informes de estudiantes de pregrado (TAPIA LADINO; BURDILES, 2009). En este ámbito, Oyanedel (2006) aborda la elaboración que realizan alumnos de Ciencias Biológicas, Ciencias Humanas y Ciencias Sociales sobre las figuras del productor y del receptor en sus textos. Destaca como un rasgo específico de las dos últimas áreas las marcas 
de didacticidad (MOIRAND, 1992) y concluye que la variedad e inestabilidad en las estrategias usadas para construir a los actores involucrados responden a las diferencias que son propias del campo disciplinar y de la clase de informe y, por otra parte, al nivel de alfabetización en el que se encuentran los productores.

Dentro de la Escuela Lingüística de Valparaíso el informe se ha caracterizado como un "género discursivo cuyo macro propósito es consignar situaciones, procedimientos y/o problemas. Idealmente, su contexto de circulación es el ámbito laboral y la relación entre los participantes es entre escritor experto y lector experto. Suele ser monomodal y presentar un modo de organización discursiva que es descriptiva (PARODI, 2010, p. 276). Así este género propio del ámbito profesional puede circular también en el ámbito académico, en diferentes contextos de comprensión y producción de textos académicos. Desde la escuela de Sydney, el informe de laboratorio puede ser clasificado como una explicación procedural (MARTIN; ROSE, 2007).

Respecto de los géneros escolares, Marinkovich y equipo (2009) definen el informe de laboratorio en el contexto de la clase de Ciencias Naturales como un texto que da cuenta de "una descripción de los fenómenos observados y una interpretación de ellos en términos del conocimiento teórico con que cuenta el estudiante" (MARINKOVICH et al., 2009, p. 13). Dentro del mismo ámbito -el laboratorio escolar-, Reigosa Castro (2006) reportan una experiencia de investigación-acción en las aulas de física y química, enfatizando en el potencial epistémico del trabajo con géneros científicos. En ese sentido, para una adecuada articulación entre el currículum escolar y el universitario es preciso indagar en los diferentes componentes que están en la base de la escritura de informes de laboratorio en la universidad. Para efectos de esta investigación, definimos el informe de laboratorio en Ingeniería como: a) un texto escrito en el ámbito académico, b) producido por un estudiante universitario con el objetivo de explicar, describir e interpretar un determinado fenómeno observado, en condiciones experimentales de laboratorio, c) por medio del cual profesores y estudiantes interactúan estratégicamente con el propósito de manifestar y evaluar un grado de dominio en la competencia profesional, la que se traduce en conocimientos, habilidades, formas de hacer $\mathrm{y}$ formas de usar el lenguaje.

\subsection{Ethos y discurso académico: la construcción identitaria en el género informe de laboratorio}

El ethos discursivo -es decir, el ethos en la enunciación- se instala como parte de la construcción de identidad. En efecto, la constitución de un determinado ethos académico trae como correlato ineludible un proceso de elaboración identitaria, tal como plantea Mainguenau (2002, p. 58) cuando señala que,

En última instancia, la cuestión del ethos está ligada a la construcción de la identidad. Cada turno de habla implica a la vez tomar en cuenta las representaciones que los participantes se hacen el uno del otro; pero también la estrategia de habla de un locutor que orienta el discurso de manera de formarse a través de él una cierta identidad.

Con todo, el ethos es un comportamiento, una manera de moverse en el espacio social; esto implica que no se manifiesta solamente como un rol o como un estatuto, sino que también como un cuerpo y una voz y, en ese sentido, tiene un carácter dinámico, en permanente construcción. El ethos "muestra la forma en que el sujeto que habla construye su identidad integrándose a un espacio estructurado que le asigna su lugar y su papel" (AMOSSY, 2010: 38). De esta manera, se plasma como una zona de referencias internas por medio de la cual el yo de la enunciación va informando al tú datos acerca de su identidad. Por eso, Barthes (1974) concibe al ethos como una connotación: "son los rasgos de carácter que el orador debe mostrar al auditorio" (1974, p. 143).

Este proceso identitario se torna relevante cuando está en juego la incorporación de los sujetos a una comunidad a través de los discursos. Mainguenau (1987) propone tres elementos clave a través de las cuales se accede a una comunidad portadora de saber: a) el proceso de incorporación, de admisión por parte de los sujetos de las representaciones sociales y de esquemas culturales que definen una forma específica de habitar en el mundo; b) la incorporación pone en evidencia la forma en que los discursos proveen una determinada corporalidad a la figura del enunciador y del destinatario a partir de determinados rasgos lingüísticos y paralingüísticos; c) se logra el proceso de incorporarse imaginariamente, de adherirse a una comunidad para pasar a ser miembro de los seguidores de un específico discurso.

Desde este enfoque, la incorporación a una comunidad académica muestra la articulación entre disposiciones genéricas, modos de decir y producción de subjetividades: "la imagen discursiva desplegada por estos enunciadores se constituye a partir de un arsenal de representaciones colectivas que estipulan no solo su presentación sino también la eficacia de su saber en una cultura dada" (VÁSQUEZ, 2009, p.172). Esto se vincula asimismo con las nociones de comunidad discursiva y género en los términos propuestos por Swales: "las convenciones respecto a una terminología especializada, la adecuación de temas, la estructura y la función de los elementos discursivos regula el funcionamiento de una comunidad científica" (1990, p.58). Una comunidad 
discursiva posee textos y prácticas en común y enfatiza elementos cruciales del contexto, el conocimiento de la situación social y cultural, el conocimiento del mundo, de los interlocutores, de los textos, de las normas y, en ese sentido, está estrechamente ligada con la noción de competencia comunicativa o de competencia discursiva, la que "Exige de cada sujeto que se comunica e interpreta que esté en capacidad de manipular (Yo) - reconocer (Tú) las estrategias de puesta en escena que se desprenden de las necesidades inherentes al marco situacional" (CHARAUDEAU, 2001, p. 5). Desde esta perspectiva, la construcción del ethos se vincula fuertemente con las nociones de competencia discursiva y de estrategia de discurso.

En una interacción oral o escrita, entonces, las estrategias son obra de un individuo o de una colectividad que, de modo consciente o no, tiende a seleccionar un cierto número de operaciones de lenguaje más o menos convencionalizadas, cuyo uso se impone en virtud de un contexto determinado (CHARAUDEAU; MAINGUENEAU, 2005). Para Charaudeau (2006), esta noción es posible de ser usada de acuerdo con el contrato de comunicación que asegura la estabilidad y previsibilidad de las conductas. En otros términos, quienes interactúan estratégicamente, lo hacen considerando un contrato comunicacional preexistente.

Definimos operacionalmente ethos académico como la imagen construida discursivamente por el autor del texto para presentarse a sí mismo como un escritor académico capaz de organizar y conducir su texto; es decir, un escritor que domina las convenciones de la tradición académicocientífica -en este caso de las Ciencias de la Ingeniería-y que es a su vez capaz de gestionar el proceso de escritura para producir un discurso claro, neutro y verdadero, acorde a la situación comunicativa en juego.

Nuestro objetivo por tanto es, por un lado, analizar las estrategias discursivas y los recursos lingüísticos que son empleados por los estudiantes en la construcción de un ethos académico y por otro lado, relacionar esta construcción identitaria con informes considerados exitosos y con informes categorizados como deficientes por el profesor que demanda la producción de este género de formación. Esto nos permitirá alcanzar una primera aproximación al papel que cumple la gestión de las voces enunciadoras en la construcción de textos académicos efectivos, profusamente estudiado en géneros expertos, pero no así en el discurso académico y científico en formación. Asimismo, problematizar el papel del sujeto y de la identidad en la reflexión sobre los textos.

\section{La propuesta investigativa}

La presente investigación busca examinar cómo se construye el ethos académico en informes de laboratorio producidos por estudiantes universitarios de pregrado. Se postula que este género de formación responde a un contrato de comunicación específico, ya que es el resultado de prácticas sociales en relación con otros. El propósito consiste en evaluar tanto un grado de dominio disciplinar, una habilidad cognitiva, así como el manejo de las características lingüísticas y comunicativas del discurso académico en el contexto de prácticas de laboratorio. La estructura retórica del género es: introducción, marco teórico, datos experimentales, análisis, conclusiones y bibliografía.

Basados en los presupuestos teóricos, la fase analítica contempla la caracterización genérica del tipo de texto en estudio a través de la especificación de su contrato de comunicación (CHARAUDEAU, 2006). En el nivel léxico-gramatical se pesquisan las estrategias y recursos lingüísticos en la totalidad del corpus. En el nivel discursivo-semántico se identifican las diferentes funciones que cumplen estas estrategias y recursos en relación con la construcción de una imagen discursiva en los textos. En el nivel interpretativo, se explora la relación entre la constitución de un ethos académico y el grado de aceptación o rechazo que tiene el informe elaborado por parte del docente evaluador.

\section{METODOLOGÍA}

\subsection{El Corpus y su contextualización}

El corpus está conformado por nueve informes de laboratorio producidos por estudiantes de pregrado de la carrera de Ingeniería Civil Eléctrica de la Facultad de Ciencias Físicas y Matemáticas de la Universidad de Chile. A continuación se presenta en detalle las características de los informes. Para los propósitos de este estudio, se han establecido dos tipos de informes clasificados según el criterio de calificación obtenida en base al proceso de evaluación del docente: informes A (calificación aceptable o adecuada), informes D (calificación deficiente).

Tabla 1 - Detalle del corpus

\begin{tabular}{lcc}
\hline Tipo de informe & Cantidad & № de palabras \\
\hline A Calificación adecuada (5.0-7.0) & 5 & 13.905 \\
D Calificación deficiente (2.0-4.9) & 4 & 6.550 \\
\hline
\end{tabular}

Fuente: Elaboración propia.

En la siguiente tabla, es posible apreciar las características más específicas de este corpus, formado por textos originados en el marco del curso Laboratorio de Ingeniería Eléctrica (EL3003), que se ofrece en el sexto semestre (tercer año) de desarrollo de la carrera, y pertenece al ciclo formativo de obtención de la licenciatura en Ciencias de la Ingeniería mención Eléctrica. Todos los estudiantes firmaron consentimiento informado para el desarrollo de esta investigación con los detalles bioéticos. 
Cuadro 1 - Tipo de informe y temática

\begin{tabular}{|c|c|l|}
\hline Código informe & Grupo & Tema \\
\hline INF01 & A & Celdas Peltier \\
\hline INF02 & A & Rectificadores trifásicos no controlados \\
\hline INF03 & A & Sensores magnéticos \\
\hline INF04 & A & Modulación FM \\
\hline INF05 & A & Modulación PSK \\
\hline INF06 & D & Rectificadores trifásicos \\
\hline INF07 & D & Circuitos trifásicos \\
\hline INF08 & D & Circuitos trifásicos \\
\hline INF09 & D & Rectificadores trifásicos no controlados \\
\hline
\end{tabular}

Fuente: Elaboración propia.

\subsection{Procedimientos analíticos}

El acercamiento al objeto de estudio se realiza por medio de una metodología básicamente de corte cualitativo, el estudio es de corte descriptivo. Los pasos metodológicos seguidos son los siguientes:

3.2.1 A partir de la revisión bibliográfica, se determinaron cuatro categorías básicas o variables observables.

Cuadro 2 - Categorías a explorar a partir de la revisión bibliográfica

\begin{tabular}{|l|l|l|}
\hline Categoría & Definición & Manifestaciones \\
\hline Deixis personal & $\begin{array}{l}\text { Emergencia del } \\
\text { Locutor/ Sujeto de la } \\
\text { enunciación: para referir } \\
\text { la imagen discursiva } \\
\text { del autor de un trabajo } \\
\text { científico/académico } \\
\text { (TORDESILLAS; }\end{array}$ & $\begin{array}{l}\text { - Pronombres personales } \\
\text { - Flexión verbal }\end{array}$ \\
\hline $\begin{array}{l}\text { REGRONI, 2001). } \\
\text { parafrástica }\end{array}$ & $\begin{array}{l}\text { Operación reflexiva en } \\
\text { que la referencia se hace } \\
\text { sobre un enunciado } \\
\text { emitido anteriormente } \\
\text { (CIAPUSCIO, 2007). }\end{array}$ & - Marcadores discursivos \\
\hline Metadiscurso & $\begin{array}{l}\text { Comentar el propio decir, } \\
\text { poner de manifiesto la } \\
\text { actitud de control y de } \\
\text { monitoreo del sujeto } \\
\text { respecto de la enunciación } \\
\text { que está llevando a } \\
\text { cabo CIAPUSCIO, 2007; } \\
\text { MONTOLIO, 2010; } \\
\text { HYLAND, 2011). }\end{array}$ & $\begin{array}{l}\text { - Palabras entrecomilladas } \\
\text { HOClosas metadiscursivas }\end{array}$ \\
\hline
\end{tabular}

Fuente: Elaboración propia.

3.2.2 A continuación, se desarrolló una caracterización del género discursivo a partir del contrato de comunicación.

3.2.3 Se realizó un análisis manual a partir de la revisión analítica y detallada de los materiales y se identificaron los fenómenos comunes y divergentes entre ambos tipos de informes.
3.2.4 Por último, se establecieron las características del ethos académico que surgen del análisis de los datos y algunas consecuencias para la conformación de las identidades discursivas.

\section{Resultados y Discusión}

\subsection{El informe de laboratorio como contrato de comunicación}

En esta investigación, adscribimos a la noción de género situacional en los términos propuestos por Charaudeau (2006), y por lo tanto, el informe de laboratorio como género responde a condiciones que conforman un determinado contrato de comunicación: así las cosas, podemos determinar en estos discursos una finalidad o propósito socialmente reconocido. Asimismo, estos discursos se caracterizan por poseer una comunidad de participantes, asuntos o temas invocados y estar inscritos en circunstancias materiales específicas.

El contrato global del ámbito de la comunicación con sus variantes, por lo que remite a las circunstancias situacionales; en la organización discursiva y sus modos, por lo que remite a las restricciones específicas emanadas de las circunstancias situacionales; en las formas textuales, por lo que remite a las ocurrencias formales que dan cuenta de las regularidades, incluso rutinas, de la configuración textual (CHARAUDEAU, 2004, p. 35).

En ese ámbito, la propuesta de Charaudeau (2004) enfatiza que una definición de los géneros implica la articulación entre los tres niveles mencionados: a) del contrato situacional, b) de las restricciones discursivas y c) de las restricciones formales; así quienes interactúan estratégicamente lo hacen a partir de un contrato de comunicación preexistente, que puede equipararse a la escena englobante de Mainguenau (2002). Esto cobra relevancia ya que "El locutor debe trabajar su ethos en función del papel determinante de los géneros antes y durante la producción discursiva" (BERMÚDEZ, 2007, p.20).

En este sentido, un primer paso del análisis consiste en definir el contrato de comunicación específico que nos permita tener una caracterización detallada del género discursivo bajo examen. En la tabla siguiente es posible apreciar los principales elementos del contrato de comunicación que configura el género situacional: informe de laboratorio.

Las coordenadas arriba expuestas funcionan como un marco de referencia para la construcción del sentido, un marco co-intencional para los hablantes. Estos elementos configuradores de la situación de comunicación son relevantes para explorar las dinámicas de interacción en 
la construcción de un ethos discursivo particular, ya que "El contrato es de lo que se habla antes de que cualquiera haya hablado, lo que es comprendido incluso antes de que se haya leído" (CHARAUDEAU, 2006, p. 42). En este sentido, el informe de laboratorio se encuentra vinculado a las prácticas discursivas de la Universidad como institución. En efecto, existe un discurso institucional que integra un discurso disciplinar en específico y en ese sentido, las formas de usar el lenguaje en las diferentes comunidades de práctica está constreñido no sólo por factores disciplinares y temáticos sino que también por las características institucionales, la presentación de discursos académicos debe quedar a cargo de un vocero legitimado (BOURDIEU, 1987), así como por elementos identitarios que permean la construcción progresiva de una voz académica y científica por parte del estudiante universitario.

Cuadro 3 - Contrato de comunicación del género Informe de laboratorio

\begin{tabular}{|c|c|}
\hline $\begin{array}{l}\text { Finalidad } \\
\text { ¿Estamos aquí para } \\
\text { decir qué o para hacer } \\
\text { qué? }\end{array}$ & $\begin{array}{l}\text { Dar cuenta de un estado de conocimiento } \\
\text { experiencial: los informes de laboratorio } \\
\text { presentan alguna experiencia realizada, } \\
\text { destacando qué se hizo, cómo fue realizado, } \\
\text { los resultados obtenidos y el análisis que se } \\
\text { puede realizar de estos. Lo fundamental de } \\
\text { un buen informe de laboratorio es que permita } \\
\text { al lector replicar el experimento, de modo de } \\
\text { que se pueda comprobar la veracidad de la } \\
\text { información, en caso de ser necesario. }\end{array}$ \\
\hline $\begin{array}{l}\text { Identidad } \\
\text { ¿Quién le habla a } \\
\text { quién? }\end{array}$ & $\begin{array}{l}\text { Enunciador: Estudiante universitario de } \\
\text { pregrado de tercer año. (inexperto, aprendiz) } \\
\text { Destinatario: Docente/profesor del curso } \\
\text { Laboratorio de Ingeniería Eléctrica. Académico } \\
\text { del departamento de Ingeniería Eléctrica. } \\
\text { (Experto, especialista, Doctor en Sistemas de } \\
\text { potencia). } \\
\text { Se establece por tanto un tipo de } \\
\text { interrelación asimétrica entre un docente y } \\
\text { un estudiante. }\end{array}$ \\
\hline $\begin{array}{l}\text { Campo de saber } \\
\text { ¿A propósito de qué? }\end{array}$ & $\begin{array}{l}\text { Contenido temático de la asignatura: Datos } \\
\text { experimentales, mediciones, unidades de } \\
\text { medida y variables de la experiencia en el } \\
\text { campo de la Ingeniería Eléctrica. }\end{array}$ \\
\hline $\begin{array}{l}\text { Dispositivo } \\
\text { ¿En qué marco físico } \\
\text { espacial y temporal? }\end{array}$ & $\begin{array}{l}\text { Escrito computacional } \\
\text { Primer semestre académico, otoño año } 2015 . \\
\text { Facultad de Ciencias físicas y Matemáticas } \\
\text { Universidad de Chile. Santiago de Chile. }\end{array}$ \\
\hline
\end{tabular}

Fuente: Elaboración propia basada en las condiciones del contrato comunicacional (CHARAUDEAU, 2001, 2004, 2006).

Es así que la escritura y la construcción del ethos implica tensiones, implica transitar por un espacio de obligaciones y por un espacio de estrategias, lo que acarrea un arduo y complejo proceso de convertirse en autores, en escritores académicos, en definitiva en poder escribir y hablar Ingeniería: "Emisor y receptor, sujeto comunicante y sujeto interpretante, son a la vez predeterminados y libres. Predeterminados en parte por el acuerdo de contrato, libres en la construcción de los acuerdos personales y de los efectos que estos implican"
(CHARAUDEAU, 2006, p. 49). De esta manera, como en todo discurso el sujeto que reporta un experimento se construye a sí mismo en la instancia de la enunciación: el ethos alude a la presencia del orador en su discurso y está estrechamente relacionado con la imagen que se desprende de él y en ese sentido, siguiendo a Mainguenau (1987) "puede analizarse a través de ciertas marcas discursivas que, a la vez que esconden, localizan y revelan la subjetividad del enunciador". En el apartado siguiente nos enfocaremos en las estrategias discursivas y en los recursos lingüísticos que posibilitan la construcción de un ethos académico. Para esto ejemplificaremos con el corpus y pondremos en relación aspectos teóricos y empíricos. A medida que se desarrolle este análisis se irán profundizando aspectos internos y externos del contrato de comunicación ya descrito.

\subsection{Estrategias discursivas y recursos lingüísticos en la construcción de un ethos académico}

El uso de pronombres personales (deixis personal) es la primera categoría que debemos analizar, ya que se trata del lugar característico para observar las huellas del escritor en su texto ${ }^{1}$. En relación con el empleo de la primera persona plural este se registra en ambos tipos de informes, pero con mayor profusión en los informes A. Este recurso lingüístico se manifiesta a través de la flexión verbal -mos y a través del pronombre átono nos:

(1) Este comportamiento nos permite afirmar que si invertimos la polaridad de la fuente de alimentación, la cara fría ahora calentará y la cara caliente sufrirá un descenso de temperatura. (INF01, grupo A).

(2) El núcleo ferromagnético del imán, al estar sometido a un campo magnético adquiere magnetización, y esta magnetización es mantenida por un periodo de tiempo en el sensor aún en ausencia del campo que la generó. De esta forma obtenemos que el sensor detecta un campo aún en ausencia de éste, es decir un falso positivo. (INF02, grupo A).

(3) Si comparamos los valores de tensión y corriente encontrados en el rectificador de media onda con los ahora obtenidos, se puede observar que aumentaron considerablemente, debido a que la rectificación de onda completa, aprovecha además cada semiciclo negativo, lo que aumenta directamente los valores de tensión (tanto tensión media como RMS) (INF08, grupo B).

\footnotetext{
1 Las convenciones utilizadas en este artículo son las siguiente: Estrategias deícticas y de reformulación (negrita y subrayado).

Tipos de verbos importantes para el análisis discursivo (negrita).

Metadiscurso (subrayado).
} 
Desde el punto de vista de su función en la enunciación, el único uso del nosotros que se registra en el corpus es el denominado nosotros de autor: su uso se encuentra ampliamente documentado en la literatura especializada y da cuenta de cómo "el locutor habla en nombre de la comunidad científica, autorizado mediante un contrato enunciativo por el que se yergue en delegado de dicha colectividad" (GARCÍA NEGRONI; TORDESILLAS, 2001, p. 84). Asimismo, permite al locutor integrar a su auditorio de manera que comprenda e interiorice tanto el contenido como la práctica de experimentación. De esta manera se puede entender también como una marca de didacticidad (MOIRAND, 1992).

$\mathrm{Si}$ bien predomina en todo los informes la despersonalización, rasgo característico en los textos científicos, manifestada a través del uso de estructuras pasivas, nominalizadas y uso de formas no finitas, entre otros elementos, la presencia de la primera persona plural se manifiesta en todo el corpus y de forma mayoritaria en los informes del grupo A, es decir en aquellos calificados como aceptables, lo que pone en evidencia que una mayor impersonalización no asegura por sí sola la emergencia de una imagen más académica y/o más científica. En este caso, el uso del nosotros de autor colabora en construcción de una explicación del tipo "hacer saber" al destinatario con la finalidad de que el objeto se vuelva más accesible a la comprensión. Se utiliza de esta manera la explicación para evidenciar el aprendizaje logrado con la experiencia en el laboratorio: de ahí el uso de los verbos fácticos: obtenemos, invertimos, comparamos, entre otros. Así las cosas, los procedimientos explicativos se transforman en estrategias argumentativas para convencer al evaluador del dominio de determinados contenidos conceptuales y procedimentales. En efecto se construye desde el lugar del saber para construir así un ethos creíble a partir de la claridad expositiva.

En estrecha relación con lo anterior, una segunda estrategia que podemos identificar es la frecuente utilización del verbo de percepción o cognición ver, el que se incluye en diferentes sintagmas con los que se apela a la fuerza de lo evidente:

(4) En el rectificador de media onda se ve que puede soportar una corriente de hasta $72 \mathrm{~mA}$, mientras que en el rectificador de onda completa existen corrientes $\tan$ pequeñas que no se han obtenido lecturas. Cabe destacar, que la corriente se mide en una resistencia de $0.1 \Omega$, por lo que fluye una corriente muy pequeña. (INF02, grupo A)

(5) Podemos ver con estos resultados de forma clara el efecto de la histéresis en las mediciones. El núcleo ferromagnético del imán, al estar sometido a un campo magnético adquiere magnetización, y esta magnetización es mantenida por un periodo de tiempo en el sensor aún en ausencia del campo que la generó. (INF05, grupo A)

(6) Además, observando el espectro de Fourier de ambas se puede ver que el rizado de la señal demodulada está caracterizado por una banda de frecuencias altas centrada en las cercanías de 175kHz. (INF04, grupo A)

Mediante esta selección verbal, los hechos se ven, se recurre a la fuerza de lo evidente y a través de la marca de primera persona plural "-mos" el examinando interactúa con el auditorio apelando a un sujeto cognitivo y perceptivo. En el caso de (5) este uso del verbo en infinitivo se combina con un nosotros inclusivo que toma forma de referencia pseudoinclusiva (cf. HAVERKATE, 1999; NIETO; OTERO, 2004) que sirve para crear la impresión de que el oyente comparte el punto de vista del hablante.

Se trata, entonces, de borrar las marcas valorativas, en una especie de movimiento pendular que pasa desde un tipo de discurso de carácter experiencial (perspectiva cognoscitiva) a un discurso de tipo más institucional (ROBERTS et al., 2000) que destaca lo mostrado (perspectiva visual), los hechos, datos y experiencias. A través de estas estrategias, el estudiante construye un ethos que aspira a la precisión, a la neutralidad, a la transparencia: los datos se ven, el fenómeno observado y percibido es lo se releva dentro del discurso explicativo. Los informes pertenecientes al grupo deficiente utilizan en menor cantidad esta tipo de estructuras: en concreto un informe de los cuatro pertenecientes a este grupo; en cambio aquellos informes que pertenecen al grupo utilizan estas combinaciones para construir un discurso claro, neutro y verdadero, pero eso no le resta la fuerte orientación argumentativa que estos textos poseen ya que están centrados en el uso de estrategias que intenta "convencer" al destinatario a partir del "explicar" (SAVIO, 2009, p.256) los análisis y resultados de los experimentos.

Otra estrategia discursiva que predomina es la reformulación o el uso de la paráfrasis. Se trata de un procedimiento discursivo que emerge en los informes analizados a través del uso del conector "es decir", cuyas funciones revisamos en detalle en Castillo y Sologuren (2017). Entendemos reformulación, siguiendo a Maingueneau (2003, p. 84), como reformulación interdiscursiva que implica la transformación de un texto en otro texto y que permite que el enunciador negocie los obstáculos que van surgiendo: hipótesis sobre la identidad, los saberes del co-enunciador o problemas ligados a las imágenes (necesidad de construir un vínculo 
social positivo). Operación discursiva, por lo tanto, que lleva a reexaminar el contexto previo. Las operaciones de reformulación, las cuales son muy frecuentes en diferentes géneros académicos (GARCÍA NEGRONI, 2009) no solo constituyen herramientas para la cohesión y progresión textual, sino que también en la configuración de una determinada imagen del autor o ethos: "En sus esfuerzos por lograr una reformulación más precisa, más adecuada, más conforme a su perspectiva enunciativa y destinada a orientar, o a incluso imponer, una cierta interpretación en el lector" (GARCÍA NEGRONI, 2009, p. 48). En este sentido, la reformulación colabora en la construcción de un ethos académico que muestra en espectáculo el esforzado trabajo de dar con la mejor expresión, con la mejor explicación y así conducir su discurso hacia la interpretación deseada. Revisemos algunos ejemplos:

(7) Dados los valores medidos en la tabla 3, para rectificadores de media onda la tensión máxima no cambia significativamente, no obstante, para rectificadores de onda completa la existencia de carga inductiva reduce el voltaje máximo y una carga capacitiva reduce aún más la tensión máxima de inversa, es decir, mitigan el efecto de la tensión que debe soportar el diodo debido a la rectificación de la señal. (INF02, grupo A)

(8) Se pueden encontrar dos tipos de rectificadores: de onda completa y de media onda, entre ellos el de onda completa es el más eficiente, dado que este genera un aumento de la tensión RMS, es decir, el voltaje "observable". (INF03, grupo A)

(9) Pese a que el campo magnético generado por el imán de alta intensidad es mayor a aquel generado por su contraparte de baja intensidad, en el rango de medición límite para los respectivos imanes el campo es muy similar, es decir, el campo del imán de alta intensidad a $58.55[\mathrm{~mm}]$ es tan fuerte como el campo del imán de baja intensidad a 41.68 [mm]. (INF01, grupo A)

(10) La transmisión comienza desde el MSB (Most significative bit o bit más significativo) hacia el LSB (Less significative bite o bit menos significativo), es $\underline{\text { decir}}$, el patrón seteado en la tarjeta aparecerá invertido en el osciloscopio, por lo que en la figura 2.1.1-1 se aprecia el patrón mostrado en la tabla 2.1.1-2. (INF05, grupo A)

En estos ejemplos, se puede apreciar una reformulación parafrástica introducida por el reformulador explicativo "es decir" (PORTOLÉS, 2007, p. 146). Dentro de un tratamiento parafrástico que involucra volver a expresar de otra manera lo que se acaba de expresar, este reformulador expresa una equivalencia entre las dos formulaciones, como ocurre en los ejemplos consignados más arriba. Es así que con esta operación reflexiva el escritor académico intenta conducir, dirigir la construcción del sentido, ejerciendo un control metadiscursivo, elaborando un ethos de un escritor preocupado por su discurso y, en consecuencia, por la comprensión de los procesos experimentales. Esta estrategia en la que emergen cadenas de reformulaciones está presente en todos los informes considerados como buenos; los informes deficientes, en cambio, se caracterizan por la ausencia de una reformulación parafrástica. En general, los informes deficientes frente a la tarea de reportar los resultados del experimento, tienden a responder con gráficos e imágenes extraídas de los instrumentos, sin realizar ningún tipo de explicación, como se aprecia en el ejemplo siguiente:

Imagen 1 - INF07, grupo B

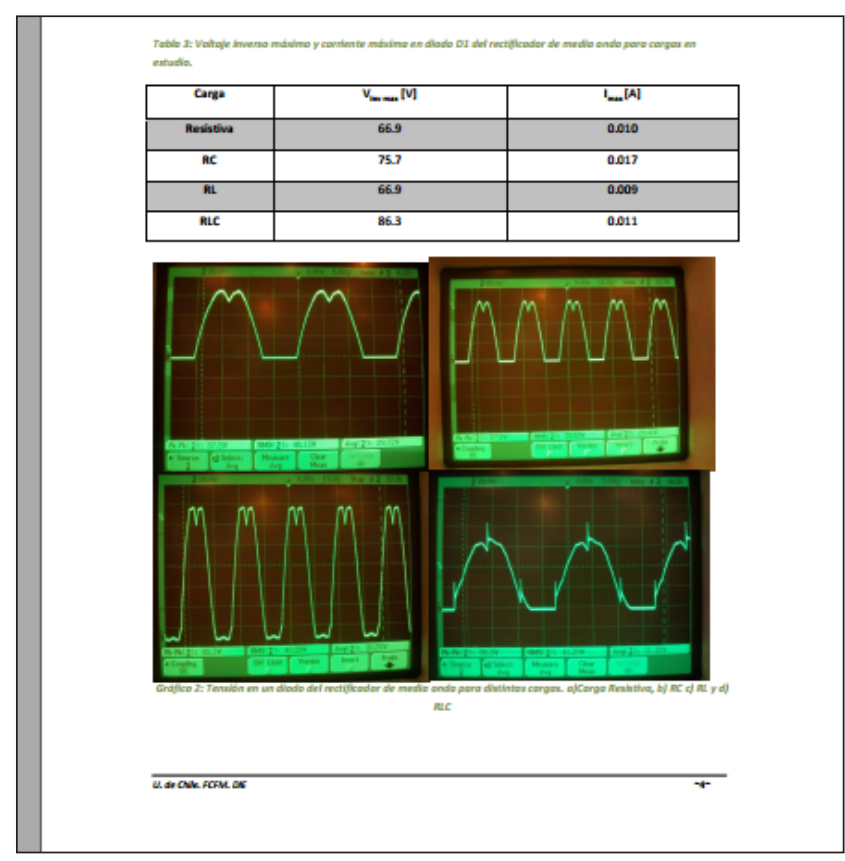

Fuente: Informe de laboratorio INF07 B del microcorpus analizado.

Esta respuesta exclusivamente no verbal muestra el desajuste entre la concepción del género situacional por parte de docentes y estudiantes. En efecto, mientras el profesor espera que las mediciones y los resultados sean comentados, explicados e incluso reconsiderados, los estudiantes que escriben estos informes dominan aún de manera muy superficial los componentes del contrato de comunicación en juego: en efecto, la extrema brevedad y concisión no posibilita la construcción de una imagen discursiva, de un ethos preocupado no sólo por exhibir los aprendizajes logrados y el manejo de una red conceptual o patrón temático de la disciplina (LEMKE, 1997), sino también por las expresiones utilizadas, las que 
son reconsideradas de forma retrospectiva a través de la estrategia discursiva de la reformulación, para encontrar así los términos más claros, más precisos, más adecuados al recorrido experimental desarrollado. En este sentido, podemos observar que junto con la complejidad del objeto disciplinar, la complejidad discursiva para dar cuenta de dicho objeto es un aspecto que debe considerarse, ya que no basta con reportar datos y cifras, el estudiante debe construirse en su texto de manera particular, atento a diversos factores externos e internos que afectan la producción del discurso.

García Negroni (2009, p. 53), en su estudio sobre la reformulación parafrástica y no parafrástica en un corpus de géneros producidos tanto por estudiantes de pregrado como por expertos disciplinares, muestra cómo la adquisición de los "modos de decir" característicos de una disciplina no se desarrolla de forma rápida ni automática. En efecto, si bien en ambos corpus -estudiantil y experto- las operaciones de reformulación parafrástica son comparables en su frecuencia, el uso de marcadores varía significativamente: así, en la escritura universitaria tienen presencia prácticamente exclusiva los marcadores "es decir" y "o", más característicos de la lengua oral, frente a la mayor diversidad de marcadores utilizados por los especialistas para introducir reformulaciones.

En el análisis sobre cómo me muestro a los demás, otro de los rasgos que se aprecian en el corpus analizado es el uso de mecanismos metadiscursivos. Se trata de un uso incipiente de herramientas discursivas en el grupo de informes A; el grupo de informe D no presenta este tipo de marcas. En concreto, se aprecia la utilización de marcadores endofóricos (HYLAND, 2002; 2005), que remiten a información que se encuentra en otros lugares del texto; este tipo de procedimiento pertenece al plano interactivo en el modelo de Hyland, plano que se caracteriza por: "The use of resources in this category therefore address ways of organising discourse, rather tan experience, and reveal the extent to wich the text is constructed with the reader's needs in mind" (HYLAND, 2013, p. 78). Básicamente los procedimientos metadiscursivos utilizados por los estudiantes universitarios corresponden a marcas predictivas (TADROS, 1994) como las siguientes:

Cuadro 4 - Marcas predictivas en informes grupo A

(12) Tal como muestra la figura a continuación

(13) Si se suministra una fuente de calor, el dispositivo termoeléctrico puede funcionar como un generador de potencia, como en la figura derecha de abajo.

(14) En el gráfico 2.1.3-1 se muestra el patrón escogido visto en el osciloscopio.

(15) Un esquema de los procesos de demodulacion es presentado en la figura 2.7, y ejemplos del proceso de demodulacion son presentados en la figura 2.8 .

Informes grupo A

Fuente: Elaboración propia.
Con esta estrategia metadiscursiva, se remite hacia recursos multimodales incorporados en el informe de laboratorio, como se puede observar en los ejemplos (12)-(15). La estrategia lingüística en estos ejemplos selecciona el material visual como campo de mostración y permite ir construyendo un ethos de aquel escritor capaz de organizar su propio discurso. Este organizador no está presente en los informes considerados deficientes. En este sentido, no se asume un rol de guía como plantea Tang y John (1999) en su pionero trabajo sobre la identidad en la escritura académica de los estudiantes universitarios.

Si bien el escritor académico tiende a ocultar el sujeto y sus valoraciones, el compromiso de quien compone el texto emerge a través de otros mecanismos, como lo son los actos prospectivos de advanced labelling (TADROS, 1994) que hemos analizado, los cuales lo comprometen a desarrollar más adelante una determinada acción. El metadiscurso es una dimensión de gran relevancia, cuyo uso incipiente se releva, como hemos visto, en los informes considerados como aceptables. Esto es consistente con las investigaciones de Hyland quien demuestra que los textos expertos de todas las disciplinas exhiben usos frecuentes de metadiscurso (HYLAND, 2005, p.55-57). En el ejemplo (16) podemos visualizar también un marcador endóforico que esta vez no tiene función prospectiva, sino que retrospectiva.

(16) Tal como se discutió en la sección anterior, el espectro de frecuencias para una señal modulada por el método FM corresponde a un espectro discreto, conformado por trenes de impulsos. (INF01, grupo A)

Los textos sin metadiscurso aparentan ser oscuros, aburridos y difíciles de seguir, por lo que no posibilitan la emergencia de un ethos que debe persuadir, de la que depende en buena parte la eficacia argumentativa de este discurso académico.

Finalmente, una última categoría que forma parte del análisis se relaciona con la gestión de las voces ajenas. Si bien todos los informes analizados presentan al final una sección de bibliografía, tan solo un informe -del grupo deficiente- reporta una fuente de manera explícita en el cuerpo del texto. Se trata de una cita aislada introducida mediante un verbo del decir que no cumple ninguna función al interior del texto y no actúa como evaluador de los aportes teóricos realizados en el marco de su disciplina.

Cuadro 5 - Uso de fuentes

El teorema de Millman dice:

"Un circuito eléctrico de ramas en paralelo, cada una compuesta por una fuente de tensión ideal en serie con un elemento lineal, la tensión en los terminales de las ramas es igual a la suma de las fuerzas

electromotrices multiplicadas por la admitancia de la rama, dividido por

la suma de las admitancias."

Jacob Millman

Fuente: INF08 
Esta selección del estudiante sigue el mismo patrón analizado con respecto al proceso de formulación de la explicación de los procedimientos: frente al requerimiento del profesor (implícito o implícito) se responde en este caso con una cita descontextualizada. Se trata de una respuesta que podríamos llamar de colocación de artefactos (imagen, cita) esperando que estos "hablen" por sí mismos, basados en un conocimiento ingenuo y superficial de las características del discurso académico/ científico que apunta a la precisión, concisión y objetividad.

El análisis nos ha permitido comprender el carácter prosódico (HALLIDAY, 1994; MARTIN; WHITE, 2005) de la construcción de la imagen de sí, es decir la constitución del ethos académico se logra por medio de una acumulación de recursos lingüísticos y estrategias en el discurso y no sólo a través de una única dimensión o categoría. Esto hace que sea tan complejo para el estudiante universitario manejar e integrar en su discurso diferentes voces, perspectivas, imágenes y figuras de la enunciación. Se trata de un proceso de construcción progresiva en la que debe ir tomando decisiones y haciendo elecciones que afectarán a planos diversos de la producción discursiva. Operan, por tanto, en la escritura académica, mecanismos finos que pueden ser llevados a la reflexión tanto desde el punto de vista teórico como práctico.

\section{Reflexiones finales}

En este trabajo, nos propusimos responder las preguntas siguientes: ¿Cómo se construye el ethos académico en los informes de laboratorio del área de Ingeniería Eléctrica? Siendo el informe de laboratorio un género de formación cuyo resultado final es evaluado por un profesor: ¿Qué relación existe entre la construcción de una determinado ethos discursivo y el éxito o fracaso estudiantil?

En relación con la primera pregunta, el análisis arroja que en este género se utiliza una diversidad de recursos lingüísticos y estrategias discursivas, lo que caracteriza el funcionamiento prosódico del ethos. En el cuadro de síntesis siguiente, pretendemos establecer una relación entre los recursos estratégicos utilizados y las características del ethos académico que se desprende del análisis discursivo, así como desde la caracterización del contrato de comunicación.

No obstante, esta asociación no debe entenderse como compartimentos estancos, sino que es el funcionamiento prosódico o el funcionamiento orquestado, en los términos propuestos por Ivanic $(1998,2005)$, en una determinada situación de comunicación lo que posibilita la constitución de un ethos académico. Frente a las tres categorías iniciales con las que nos enfrentamos al análisis discursivo, dos elementos emergen de este estudio: a) el uso de verbo de perspectiva visual ver en su combinación en diferentes sintagmas; b) la importancia que adquieren las marcas predictivas como parte de los mecanismos metadiscursivos; y c) la importancia de la explicación como estrategia para persuadir y convencer, aspecto crucial en el discurso académico. Esto pone de manifiesto que las operaciones de lenguaje son multifuncionales y que cuando estamos en presencia del análisis del nivel discursivo, las estrategias utilizadas presentan más funciones que las clásicas referidas a la conexión y progresión discursiva.

Cuadro 6 - Ethos académicos y recursos discursivos

\begin{tabular}{|l|l|}
\hline Ethos académico & Recursos estratégicos preferentes \\
\hline $\begin{array}{l}\text { Creible, objetivo, cognitivo y } \\
\text { riguroso }\end{array}$ & $\begin{array}{l}\text { Deixis personal } \\
\text { Uso del verbo de perspectiva visual: } \\
\text { ver. }\end{array}$ \\
\hline $\begin{array}{l}\text { Didáctico, explicativo, relator del } \\
\text { proceso de experimentación. }\end{array}$ & $\begin{array}{l}\text { Reformulación parafrástica: marcador } \\
\text { del discurso. } \\
\text { Mecanismos metadiscursivos. }\end{array}$ \\
\hline Preciso, claro & $\begin{array}{l}\text { Reformulación parafrástica: marcador } \\
\text { del discurso. }\end{array}$ \\
\hline $\begin{array}{l}\text { Organizador, guía y gestionador } \\
\text { del proceso de escritura }\end{array}$ & $\begin{array}{l}\text { Mecanismos metadiscursivos: marcas } \\
\text { predictivas. }\end{array}$ \\
\hline
\end{tabular}

Fuente: Elaboración propia.

En relación a la segunda pregunta, el análisis sobre la construcción del ethos en textos producidos por estudiantes que se encuentran en etapas tempranas e intermedias de sus estudios universitarios muestra que los aspectos vinculados a la imagen del escritor, a las voces enunciadoras, a las mecanismos de posicionamiento, en definitiva a la construcción de la identidad discursiva, no son superfluos ni accesorios, aún en las ciencias llamadas "duras" a las que pertenece nuestro corpus. En efecto, la construcción de un ethos académico, de una voz autoral, es un desafío para los estudiantes que es crucial que aprendan a manejar, ya que el problema de la constitución de un ethos está estrechamente relacionado con la manera cómo las comunidades y los escritores conciben los géneros y las prácticas de lectura y de escritura al interior del aula universitaria: estos géneros están insertos dentro de un discurso institucional, no sólo disciplinar y en ese sentido el proceso de formación de la identidad es un proceso complejo que involucra dinámicas y tensiones diversas, ya que si nos remitimos al contrato de comunicación no podemos olvidar que la escritura de estos informes se origina en la Universidad: comunidad reproductora, pero también constructora de identidades.

Así las cosas aquellos informes pertenecientes al grupo $\mathrm{D}$, aquellos que fracasan, no utilizan herramientas discursivas que les permitan ir construyendo, en diferentes momentos, una imagen de escritor académico basado 
en un dominio de la triple competencia del lenguaje propuesta por Charaudeau, es decir situacional, discursiva y semiolingüística:

\begin{abstract}
Esta triple competencia constituye en mi opinión las condiciones de la comunicación mediante el lenguaje. Que se diga que se trata de tres competencias o de una sola compuesta por tres aptitudes del hacer, lo que importa es que se aborde dicha competencia (por mi parte, tiendo a hablar de "una triple competencia del lenguaje") como el resultado de un movimiento de ida y vuelta permanente entre la aptitud para reconocer las condiciones sociales de comunicación, la aptitud para reconocer manejar las estrategias del discurso y la aptitud para reconocer manejar los sistemas semiolingüísticos, las cuales se hallan mutuamente insertadas. Esta competencia, si bien no puede ser un juicio, tal como en el uso cotidiano, es, en cambio, el resultado de un andamiaje dentro del cual se articulan saber-hacer y conocimientos. (CHARAUDEAU, 2001, p. 7).
\end{abstract}

Así, la elaboración propia de un determinado dominio conceptual, de un saber hacer y de un saber decir en una determinada comunidad de práctica universitaria, así como la evaluación de una producción discursiva que requiere cierta competencia técnica y comunicativa, involucran una negociación de suyo compleja. En dicha transacción continua de significados, las estrategias seleccionadas (de forma consciente o no) permiten a los escritores crear alineamientos diversos y posicionarse en y por el discurso de manera estratégica.

Los informes que pertenecen al grupo A se encuentran en un nivel incipiente en el dominio de las herramientas discursivas que sostienen la construcción de un ethos visible que les permita a los estudiantes expresar su aprendizaje y elaboración del conocimiento disciplinar, respetando las convenciones de la tradición académicacientífica y siendo consciente de la propia elaboración de su texto, pero más allá de eso que le posibilite conjugar diferentes roles. Justamente, no solo como un escritor académico (organizador, conductor), sino que también asuma roles en su discurso de investigador (productor, evaluador) y de especialista en la temática (representante). En este sentido, frente a la diversidad de componentes que puede involucrar un ethos académico/ científico los estudiantes se encuentran en una etapa de aprendiz, en donde actualizan básicamente una imagen de relator del proceso experimental y de guía en el texto, es necesario, por tanto seguir profundizando en la emergencia estratégica del ethos y en consecuencia, en la forma en que se incorpora el sujeto en los textos, en diferentes estadios de formación y en diferentes géneros.

Este análisis preliminar que debe ser ampliado en cuanto a corpus e instrumental analítico permite apreciar la complejidad del objeto de estudio y la necesidad de promover trabajos interdisciplinarios con especialistas en el área de la ingeniería dado: "el importante caudal de conocimiento discursivo implícito que acumula el experto sobre los discursos de su ámbito profesional" (MONTOLÍO, 2007, p. 19). Sobre todo considerando que el estudiante universitario debe orientar su práctica discursiva en tres direcciones: su saber experiencial individual, su saber disciplinar, su saber metodológico y su saber comunicar, y finalmente, su saber histórico, por el que se inserta en el ámbito de las prácticas universitarias, recontextualizadas en un ámbito específico del escenario universitario chileno.

\section{Referencias}

AMOSSY, R. La presentation de soi: Ethos et identité verbal. Paris: PUF, 2010. https://doi.org/10.3917/puf.amoss.2010.01

ARNOUX, E. Análisis Del discurso: modos de abordar materiales de archivo. Buenos Aires: Santiago Arcos Editor, 2009.

ARNOUX, E.; DI STEFANO, M.; PEREIRA, C. La lectura y la escritura en la universidad. Buenos Aires: Eudeba, 2002.

BARTHES, R. Investigaciones retóricas: la antigua retórica. Buenos Aires: Edit. Tiempo Contemporáneo, 1974.

BATHIA, V. Analysing Genre. London: Longman, 1993.

BATHIA, V. A generic view of academic discourse. In: FLOWERDEW, J. Academic discourse. Harlow: Longman, 2002. p. 21-39.

BAZERMAN, Ch. Shaping written knowledge. Madison: University of Wisconsin Press, 1988.

BAZERMAN, C. Systems of genres and the enhancement of social intentions. In: FREEDMAN, A.; MEDWEY, P. (ed.). Genre and New Rethoric. London: Taylor Francis, 1994. p. 79-101.

BERMÚDEZ, N. La noción de Ethos: Historia y operatividad analítica. Argentina: Universidad de Buenos Aires, Instituto de Lingüística, 2007.

BOGEL, F.; HJORTSHOJ, K. Composition theory and the curriculum. In: BOGEL, F.; GOTTSCHALK, K. (comp.). Teaching Prose: a guide for writing instructors. New York: Norton, 1984. p. 1-19.

BOURDIEU, P. Los tres estados del capital cultural. Sociológica, [S. l.], v. 2, n. 5, p. 11-17, 1987.

BREIVEGA, K.; DAHL, T.; FLØTTUM, K. Traces of self and others in research articles. A comparative pilot study of English, French and Norwegian research articles in medicine, economics and linguistics. International Journal of Applied Linguistics, Oslo, v. 12, n. 2, p. 218-239, 2002. https://doi. org/10.1111/1473-4192.00032 
CARLINO, P. El proceso de escritura académica: cuatro dificultades de la enseñanza universitaria. Educere: Revista Venezolana de Educación. Univ. de Los Andes, Mérida, v. 8, n. 26, p. 321-327, 2004.

CARLINO, P. Escribir, leer y aprender en la Universidad. Buenos Aires: Fondo de Cultura Económica, 2005a.

CARLINO, P. Representaciones sobre la escritura y formas de enseñarla en Universidades de América del Norte. Revista de Educación, [S. l.], n. 336, p. 143-168, $2005 b$.

CARLINO, P. Prácticas y representaciones de la escritura en la universidad: los casos de Australia, Canadá, EEUU y Argentina. Cuaderno de Pedagogía, [S. l.], v. 6, p. 6-17, 2009. https://doi.org/10.29197/cpu.v6i12.106

CASSANY, D. La cocina de la escritura. Barcelona: Anagrama, 1995.

CASTILLO, N.; SOLOGUREN, E. El reformulador $<$ es decir> en el español de Chile: Una propuesta de clasificación funcional. Lenguas Modernas, Santiago de Chile, p. 77-92, 2017.

CHARAUDEAU, P. De la competencia social de comunicación a las competencias discursivas. Revista Latinoamericana de Estudios del Discurso, Venezuela, v. 1, n. 1, p. 7-22, 2001.

CHARAUDEAU, P. La problemática de los géneros. De la situación a la construcción Textual. Revista Signos, Valparaiso, v. 37, p. 23-39, 2004. https://doi.org/10.4067/ S0718-09342004005600003

CHARAUDEAU, P. El contrato de comunicación en una perspectiva Lingüística: Normas psicosociales y normas discursivas. Opción, [S. l.], v. 22, n. 49, p. 38-54, 2006.

CHARAUDEAU, P.; MAINGUENEAU, D. Diccionario de Análisis del Discurso. Buenos Aires: Amorrortu Editores, 2005 .

CIAPUSCIO, E. Géneros y familias de género $s$ : aportes para la adquisición de competencia genérica en el ámbito académico. Ponencia presentada en Primeras Jornadas de Lectura y Escritura. Lectura y escrituras críticas: perspectivas múltiples. Tucumán, Universidad Nacional de Tucuman, 2007. Disponible en: http://www.filo.unt.edu.ar/jorn unesco/ cd/PL\%204\%20CIAPUSCIO.pdf

ESPEJO, C. La movida concluyendo en torno al tema en informes de investigación elaborados por estudiantes universitarios. Onomazein, Santiago de Chile, v. 13, p. 35-54, 2006.

FREEDMAN, A.; ADAM, C.; SMART, G. Wearing suits to class: Simulating genres and simulations as genre. Written communication, [S. l.], v. 11, n. 2, p. 193-226, 1994. https:// doi.org/10.1177/0741088394011002002
GARCÍA NEGRONI, M. Subjetividad y discurso científicoacadémico. Acerca de algunas manifestaciones de la subjetividad en el artículo de investigación en español. Revista Signos, Valparaiso, v. 41, n. 66, p. 5-31, 2008. https://doi. org/10.4067/s0718-09342014000200008

GARCÍA NEGRONI, M. Reformulación parafrástica y no parafrástica y ethos discursivo en la escritura académico en español. Letras de Hoje, Porto Alegre, n. 44, p. 46-56, 2009.

GARCÍA NEGRONI, M.; TORDESILLAS, M. La enunciación en la lengua: de la deixis a la polifonía. Madrid: Gredos, 2001.

HALLIDAY, M. A. K. An Introduction to Functional Grammar. 2. ed. London: Edward Arnold, 1994.

HALLIDAY, M. A. K.; HASSAN, R. Language, context, and text: aspects of language in a social-semiotic perspective. Oxford: Oxford University Press, 1989.

HALLIDAY, M. A. K.; MARTIN, J. R. General orientation. In: HALLIDAY, M. A. K.; MARTIN, J. R. Writing science: Literacy and discursive power. New York: Routledeg, 1993. p. $2-24$

HARVEY, A. Acerca de la alfabetización académica y sus prácticas discursivas. In: HACIENDO DISCURSO. Homenaje a Adriana Bolívar. Caracas: Universidad Central de Venezuela, 2009. p. 627-645.

HARVEY, A.; MUÑOZ, D. El género informe y sus representaciones en el discurso de los académicos". Estudios Filológicos, Valdivia, n. 41, p.95-114, 2006. https://doi.org/ 10.4067/S0071-17132006000100008

HAVERKATE, H. La cortesía verbal: estudio pragmalingüístico. Madrid: Gredos, 1999. https://doi. org/10.24201/nrfh.v45i2.2009

HUNSTON, S.; THOMSOM, G. Evaluation in text. Oxford: Oxford University Press, 2000.

HYLAND, K. Activity and evaluation: reporting practice in academic writing. In: FLOWERDEW, J. (ed.). Academic discourse. London: Longman, 2002. p. 115-130.

HYLAND, K. Stance and engagement: A model of interaction in academic writing. Discourse studies, [S. l.], v. 7, n. 2, p. 173-192, 2005. https://doi.org/10.1177/ 1461445605050365

HYLAND, K. Continuum companion to discourse analysis. London: Bloomsbury Publishing, 2011.

HYLAND, K. (ed.). Discourse studies reader: essential excerpts. London; New York: Bloomsbury Academic, 2013.

HYLAND, K.; GUINDA, C. Stance and Voice in Written Academic Genres. New York: Palgrave Macmillan, 2012. https://doi.org/10.1057/9781137030825 
IVANIC, R. Writing and identity: the discoursal construction of identity in academic writing. Philadelphia: Johns Benjamin, 1998. https://doi.org/10.1075/swll.5

IVANIC, R. The discoursal construction of writer identity". In: BEACH, R.; GREEN, J.; KAMIL, M.; SHANAHAN, T. (ed.). Multidisciplinary perspectives on literacy research. Cresskill, NJ: Hampton Press, 2005. p. 391-416.

LAVE, J.; WENGER, E. Situated learning: legitimate Peripherals participation. New York: Cambridge University Press, 1991. https://doi.org/10.1017/CBO9780511815355

LEMKE, J. Aprender a hablar ciencia: lenguaje, aprendizaje y valores. Barcelona: Paidós, 1997.

LOPEZ ALONSO, L. Análisis de discurso. Madrid: Síntesis, 2014.

MAINGUENAU, D. Nouvelles tendences en analyse $d u$ discours. Paris: Hachette, 1987.

MAINGUENAU, D. Problémes d'ethos. Pratiques, Paris, n. 113/114, p. 55-67, 2002. https://doi.org/10.3406/ prati.2002.1945

MAINGUENAU, D. Términos clave del análisis del discurso. Buenos Aires: Nueva visión, 2003.

MARINKOVICH, J. La escritura en la universidad: Objeto de estudio, método y discursos. Revista signos, Valparaiso, v.47, n.84, p. 40-63, 2014. https://doi.org/10.4067/s071809342014000100003

MARINKOVICH, J. et al. Aprendiendo a escribir en las disciplinas: articulación entre el currículum escolar y el universitario. Valparaíso: Ediciones Universitarias de Valparaíso, Pontificia Universidad Católica de Valparaíso, 2009. https://doi.org/10.12802/relime.13.1832

MARTIN, J.; ROSE, D. Working with Discourse: meaning beyond the clause. London: Continnuum, 2007.

MARTIN, J.; WHITE, P. The language of evaluation: appraisal in English. New York: Palgrave Macmillan, 2005. https://doi.org/10.1057/9780230511910

MILLER, C. R. Genre as social action. Quarterly Journal of Speech, [S. l.], v. 70, n. 2, p. 151-167, 1984. https://doi. org/10.1080/00335638409383686

MOIRAND, S. La présence de l'autre comme manifestation discursive d'une intention de didacticité. Cahiers de l'Institut de Linguistique et des Sciences de Langage, Lausanne, v. 2, p. 173-193, 1992. https://doi.org/10.2143/cill.18.3.2016663

MONTOLÍO, E. (coord.). Manual práctico de escritura académica. Barcelona: Ariel, 2000.

MONTOLÍO, E. Advising without Committing: The Use of Argumentative Reservation in Texts Written by Consultants. In: SARANGI, S.; GARZONE, G. (ed.). Ideology and Ethics in Specialized Communication: a discourse perspective. Berna: Peter Lang, 2007. p. 251-275.

MONTOLÍO, E.; LÓPEZ SAMANIEGO, A. Especificidades discursivas de los textos profesionales frente a los textos académicos: el caso de la recomendación profesional. In: PARODI, G. (ed.). Alfabetización académica y profesional en el Siglo XXI: Leer y escribir desde las disciplinas. Madrid: Planeta, 2010. p. 215-245. https://doi.org/10.4067/s071893032012000200012

NÚÑEZ, P., MUÑOZ, A.; MIHOVILOVIC, E. Las funciones de los marcadores de reformulación en el discurso académico en formación. Revista Signos, Valparaiso, v. 39, n. 62, p. 471-492, 2006. https://doi.org/10.4067/ S0718-09342006000300007

NIETO Y OTERO, M. Comunicación afectiva en el discurso político venezolano. Estudio del pronombre pseudo-inclusivo 'nosotros'. Spanish in Context, [S. l.], v. 1, n. 2, p. 267-284, 2004. https://doi.org/10.1075/sic. 1.2.06nie

OYANEDEL, M. Lo descriptivo en informes escritos de estudiantes universitarios. Onomázein, Santiago de Chile, v. 11, n. 1, p. 9-21, 2005.

OYANEDEL, M. Construcción temática y marcas enunciativas en los informes de estudiantes universitarios. Onomázein, Santiago de Chile, v. 1, n. 13, p.9-20, 2006.

PARODI, G. Géneros académicos y géneros profesionales: accesos discursivos para saber y hacer. Valparaíso: Ediciones Universitarias de Valparaíso, 2008.

PARODI, G. El Corpus Académico PUCV-2006: géneros escritos universitarios en cuatro disciplinas científicas. In: HACIENDO DISCURSO. Homenaje a Adriana Bolívar. Caracas: Universidad Central de Venezuela, 2009. p. 661-682.

PARODI, G. (ed.). Alfabetización académica y profesional en el siglo $X X$ : leer y escribir desde las disciplinas. Santiago de Chile: Planeta, 2010. https://doi.org/10.4067/s071893032012000200012

PARODI, G. ¿Qué se lee en los estudios doctorales?: Estudio empírico basado en géneros a través del discurso académico de seis disciplinas. $R L A$, [S. l.], v. 50, n. 2, p. 89-119, 2012. https://doi.org/10.4067/S0718-48832012 000200005

PORTOLÉS, J. Escalas informativas aditivas: pruebas del español. Spanish in context, [S. l.], v. 4, n. 2, p. 135-157, 2007. https://doi.org/10.1075/sic.4.2.02por

REIGOSA CASTRO, C. E. Una experiencia de investigación acción acerca de la redacción de informes de laboratorio por alumnos de Física y Química de primero bachillerato. Enseñanza de las Ciencias, València, v. 24, n. 3, p. 325-336, 2006. https://doi.org/10.25267/rev_eureka_ensen_divulg_ cienc.2010.v7.i3.08 
ROBERTS, C. et al. Oral examinations: equal opportunities, ethnicity, and fairness in the MRCGP. BMJ: British Medical Journal, London, v. 320, n. 7231, p. 370-375, 2000. https://doi. org/10.1136/bmj.320.7231.370

SABAJ, O. Uso de movidas retóricas y patrones léxicogramaticales en artículos de investigación en español. Implicancias para la enseñanza de la escritura científica. Boletín de Filología, [S. l.], v. XLVII, n. 1, p. 165-186, 2012. https://doi.org/10.4067/S0718-930320120001 00007

SALAGER-MEYER, F. El lenguaje de la asistencia sanitaria. In: CONGRESO INTERNACIONAL SOBRE LENGUAJE Y ASISTENCIA SANITARIA, 1., [Conferencia presentada en Mesa redonda]. Alicante, España, 2007. https://doi. org/10.1524/9783486840100.40

SAVIO, K. Sobre la defense de tesis y las estrategias discursivas en el campo de las ciencias físicas. In: ARNOUX, E. de (dir.). Escritura y producción de conocimiento en las carreras de posgrado. Buenos Aires: Santiago Arcos Editor, 2009. p. 240-258. https://doi.org/10.4067/s071809342013000300007

SWALES, J. Genre Analysis: English in academic and reseacher settings. Sydney: CUP, 1990.

SWALES, J. Research genres: Explorations and applications. Cambridge: University Press, 2004. https://doi.org/10.1017/ CBO9781139524827

SWALES, J. Variation in Citational Practice in a Corpus of Student Biology Papers From Parenthetical Plonking to Intertextual Storytelling. Written Communication, [S. l.], v. 31, n. 1, p. 118-141, 2014. https://doi. org/10.1177/0741088313515166

TADROS, A. Predictive categories in expository text. In: COULTHARD, M. (ed.). Advances in written text analysis. London: Routledge, 1994. p.69-82.

TANG, R.; JOHN, S. The 'I' in identity: Exploring writer identity in student academic writing through the first person pronoun. English for Specific Purposes, [S. l.], v. 18, p. 23-39, 1999. https://doi.org/10.1016/s08894906(99)00009-5

TAPIA LADINO, M.; BURDILES, G. Una caracterización del género informe escrito por estudiantes universitarios. Letras, [S. l.], v. 51, n. 79, p. 17-49, 2009.

TEBEROSKY, A. El texto académico. In: CASTELLÓ, M. (coord.). Escribir y comunicarse en contextos científicos y académicos. Barcelona: Graó, 2007. p. 17-46.

THOMPSON, G. Literature rewiews in applied $\mathrm{PhD}$ Theses: evidence and problems. In: HYLAND, K.; DIANI, G. (ed.). Academic evaluation and review genres. Basingstoke: Palgrave Macmillan, 2009. p. 50-67. https://doi. org/10.1057/9780230244290_4
VÁSQUEZ, G. Una ardua construcción de identidades enunciativas: memoria profesional y saber. In: ARNOUX, E. Escritura y producción de conocimientos en las carreras de posgrado. Buenos Aires: Santiago Arcos Editor, 2009. p. 169-184. https://doi.org/10.4067/s0718-09342013 000300007

Recibido en: 30/6/2019.

Aprobado en: 25/9/2019.

Publicado en: 30/11/2019.

\section{Autores:}

ENRIQUE SOLOGUREN INSUA

Doctorado, profesor, Pontificia Universidad Católica de Valparaíso (PUCV).

Orcid: https://orcid.org/0000-0001-7803-1817

E-mail: esologur@uc.cl

Dirección: Brasil 2950, Valparaíso, Región de Valparaíso, Chile

María Natalia Castillo Fadic

Doctorado, profesora asistente de la Pontificia Universidad Católica de Chile (UC).

Orcid: https://orcid.org/0000-0002-2595-7568

E-mail: mcastilf@uc.cl

Dirección: Av. Libertador Bernardo O'Higgins, 340, Santiago,

Región Metropolitana, Chile 